\title{
Endoscopic screening for malignancy in the gastric remnant: the clinical significance of dysplasia in gastric mucosa
}

\author{
GJA OFFERHAUS, ${ }^{*} \mathrm{~J}$ VD STADT, $\dagger \mathrm{K}$ HÜIBREGTSE, ${ }^{*}$ GNJ TYTGAT* \\ From the *University of Amsterdam, Department of Medicine, Division of Gastroenterology, Academic \\ Medical Centre, Amsterdam, The Netherlands, and the †Laboratory for Pathology, Edo Bergsmalaan 1, \\ Enschede, The Netherlands
}

SUMMARY Five hundred and four asymptomatic patients in whom gastrectomy had been performed between 1931 and 1960 were investigated by endoscopy plus biopsy. Ten stump carcinomas were detected $(1.98 \%)$. In five patients the tumour was limited to the mucosa and was not seen at endoscopy. In three patients with previously noted severe dysplasia intramucosal carcinoma was detected during follow up and in two the carcinoma was found at the site of the preceding severe dysplasia. True regression of severe dysplasia could not be shown. In 23 patients with previous mild or moderate dysplasia no progression was seen during follow up.

Severe gastric dysplasia is a serious marker of malignancy demanding close follow up with repeated endoscopy and biopsy. The clinical significance of mild and moderate dysplasia remains unclear. Early detection of stump carcinoma is indeed possible. Physicians should rely not so much on the endoscopic appearance but on the results of multiple biopsies.

The gastric remnant has a precancerous potential. ${ }^{\prime}$ The risk of stump carcinoma, at least in Western Europe, is estimated to be increased twofold compared with the normal population. ${ }^{23}$ The risk depends on the postoperative interval and the age at which the initial operation was performed. Patients older than 50 and those whose operation was performed more than $10-15$ years previously are particularly at risk. ${ }^{3}$

Dysplasia is considered a precancerous lesion' and patients who have undergone gastrectomy develop significantly more epithelial dysplasia than controls. ${ }^{4}$ In fact, the designation precancerous is justified in biopsy material only if the changes seen are not capable of regression; the dysplasia progresses with time and develops into a carcinoma. ${ }^{5}$

In order to evaluate the usefulness of endoscopy plus biopsy in the surveillance of patients who have undergone gastrectomy and to analyse the clinical importance of dysplasia as a precancerous lesion, we investigated 504 asymptomatic patients by endoscopy with multiple biopsies.

Accepted for publication 4 April 1984

\section{Material and methods}

We collected the data of 2633 consecutive patients in whom stomach operation had been performed for benign disease in our hospital between 1931 and 1960. At the start of the study 874 patients had already died; all the remaining patients were invited to participate. A total of 1255 patients could not be traced or refused to take part; thus 504 patients participated in our endoscopic-biopsy screening programme.

Details of the patients participating in the study are given in Table 1 . The mean interval from the initial resection till the first endoscopic investigation was $24 \cdot 2$ years (range $15-46$ ) and the mean age at the time of the first endoscopy was 62.3 years (range 37-91).

In all patients endoscopy was performed with a forward viewing or 70 degree fibrescope. Six to ten forceps biopsies were routinely taken from the stomal region, three from the lesser and three from the greater curve, in a standard way. More biopsies were taken when abnormalities were present. All the patients were invited for a second investigation 
Table 1 Details of patients participating in endoscopic screening programme.

\begin{tabular}{lc}
\hline & No of patients \\
\hline Men & 456 \\
Women & 48 \\
Initial complaint & 119 \\
Benign gastric ulcer & 344 \\
$\quad$ Duodenal ulcer & 41 \\
Other benign or unknown conditions & \\
Previous surgery & 34 \\
$\quad$ Bilroth I anastamosis & 470 \\
Bilroth II anastamosis & \\
\hline
\end{tabular}

two years after the first endoscopy. In 157 patients a follow up examination was performed. Patients with severe gastric dysplasia were followed more frequently, at intervals of six months.

All the biopsy specimens were read "blind" by the same experienced pathologist and the grade of dysplasia was described. The histological criteria of gastric dysplasia were based on the report of the WHO expert committee on precancerous conditions of the stomach.' At this meeting dysplasia was defined as changes with the following three histological features: (1) cellular atypia, (2) abnormal differentiation, (3) disorganised mucosal architecture. According to the severity of the changes the dysplasia is classified into three grades: mild, moderate, and severe.

Mild dysplasia-grade I. The epithelium exhibits active orderly proliferation which exceeds that of normal epithelium. There is expansion of the pro- liferative zone. This is manifested by a raised mitotic number and a loss of differentiation in favour of the proliferatively active cells. The mucus production is reduced and a number of cells are encountered in the $S$ and $G_{2}$ phases, characterised by large and darkly stained nuclei. The gastric pits are elongated and tortuous. This lesion may be seen in any trivial inflammation (Fig. 1).

Moderate dysplasia-grade II. If increased cell renewal persists more profound alteration of the mucosal architecture results. This is manifested histologically as a further increase in the number of undifferentiated cells with large, hyperchromatic nuclei which show moderate degrees of pleomorphism. Frequent mitotic figures may be encountered in all parts of the foveolae. Disturbances of mitoses are sometimes demonstrable. There is a total lack of mucus formation and pseudostratification in various degrees is present. The atypical foveolar tubules show elongation and branching but are separated by a distinct layer of stroma between them. In grade II dysplasia the mucosa almost always shows foveolar hyperplasia or intestinal metaplasia - that is, recognisable pre-existing patterns (Fig. 2).

Severe dysplasia-grade III. In this lesion the cytonuclear atypia is comparable with that in cancer. The glands are bordered by pseudostratified pleomorphic, basophylic, non-mucus secreting cells. Nuclei are irregular, hyperchromatic, and voluminous with large nucleoli. Abnormal mitotic figures are

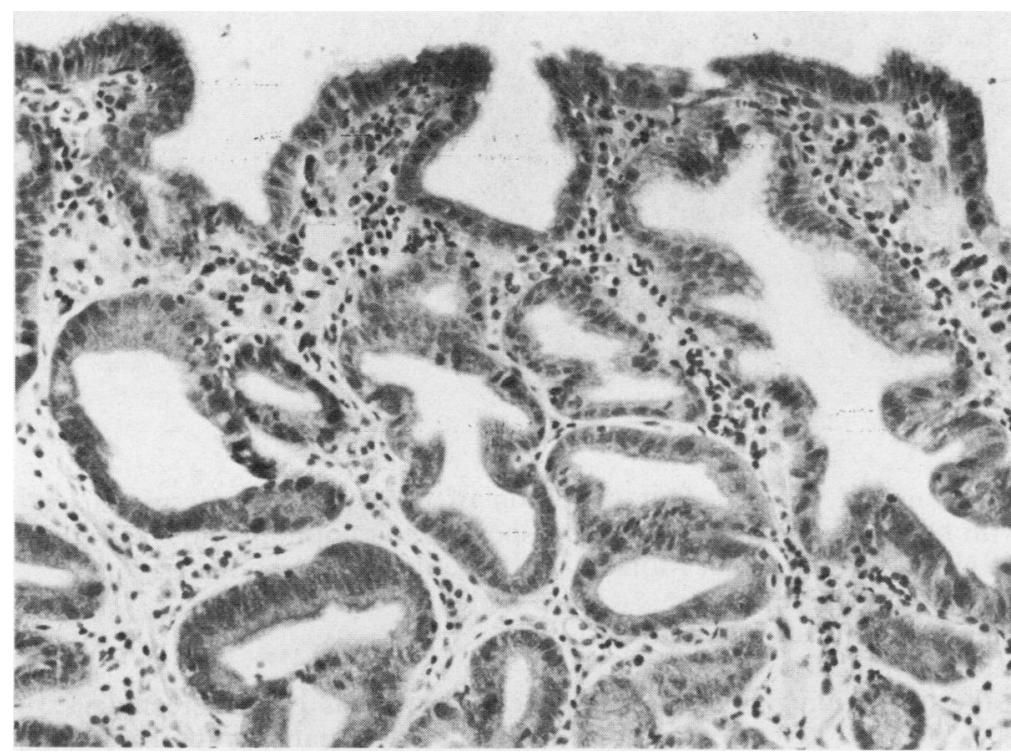

Fig. 1 Example of the microscopic picture of mild dysplasia-grade $I$. Haematoxylin and eosin. $\times 200$. 


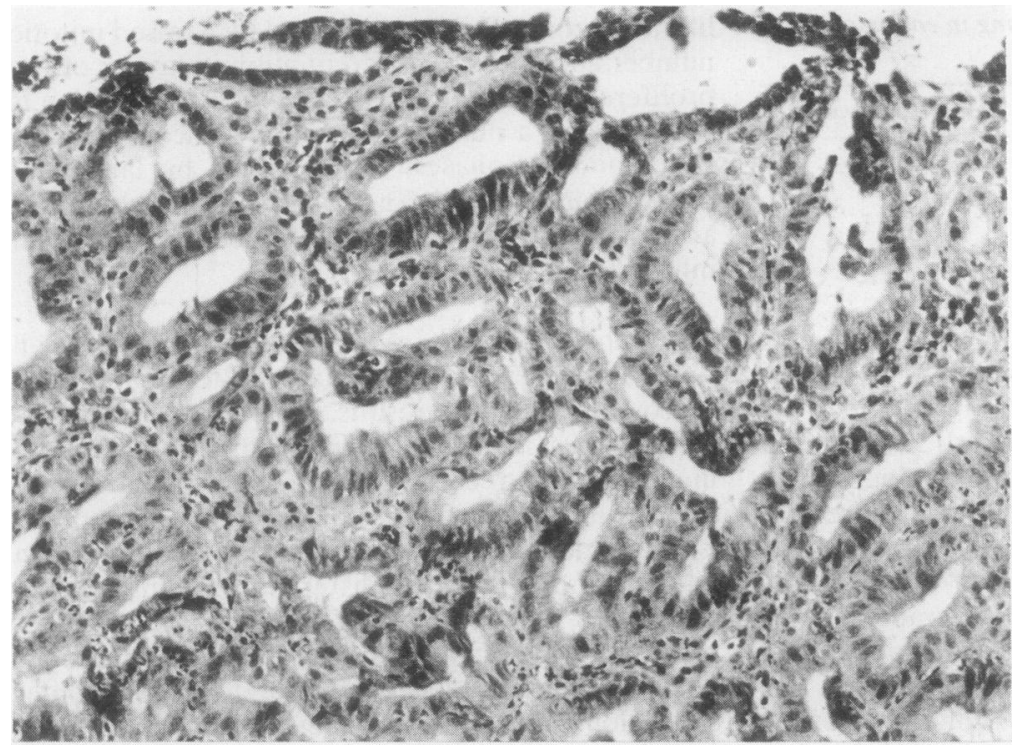

Fig. 2 Example of the microscopic picture of moderate dysplasia-grade II. Haematoxylin and eosin. $\times 200$.

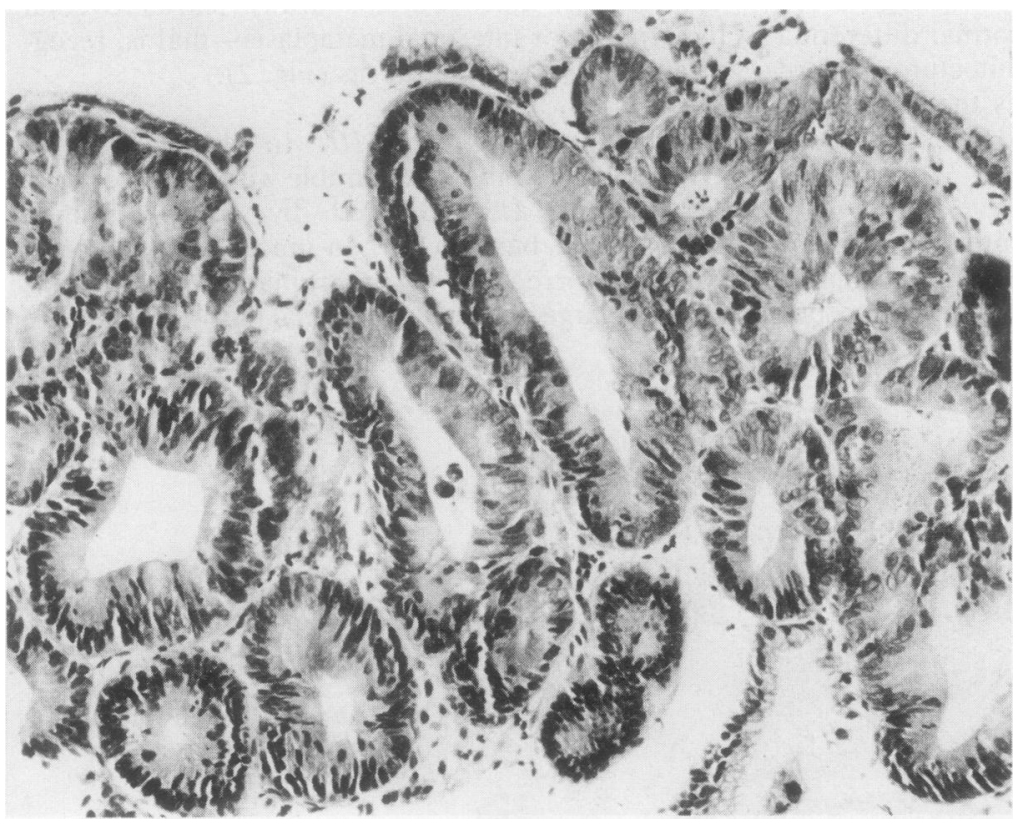

Fig. 3 Pseudostratified epithelium with hyperchromic nuclei in closely packed tubules, typical of severe dysplasia. Haematoxylin and eosin. $\times 250$.

occasionally seen. The original structure of the mucosa is almost completely lost with back to back packing and fusion of neighbouring glands; irregularly branched or papillary glands may be visible (Fig. 3). Severe dysplasia is sometimes very difficult to differentiate from incipient cancer, but in the latter invasive or infiltrative growth in the surrounding tissue has to be shown. 
Table 2 Details of 10 patients with post-gastrectomy cancer detected by endoscopy plus biopsy

\begin{tabular}{lllllll}
\hline Sex & $\begin{array}{l}\text { Age at the time } \\
\text { of diagnosis (yr) }\end{array}$ & $\begin{array}{l}\text { Indication for the } \\
\text { initial operation }\end{array}$ & $\begin{array}{l}\text { Initial operative } \\
\text { procedure }\end{array}$ & $\begin{array}{l}\text { Cancer free } \\
\text { interval (yr) }\end{array}$ & Operative specimen & $\begin{array}{l}\text { Type of gastric } \\
\text { carcinoma }\end{array}$ \\
\hline M & 73 & Duodenal ulcer & Billroth II & 26 & Inoperable \\
M & 83 & Pyloric stenosis & Billroth II & 36 & Inoperable \\
F & 60 & Duodenal ulcer & Billroth II & 25 & Positive lymph node \\
Infiltration muscularis propria. No \\
M & 70 & Billroth II & 38 & $\begin{array}{l}\text { metastasis } \\
\text { Infiltration submucosa. No metastasis II a-b Multicentric }\end{array}$ \\
M & 60 & Duodenal ulcer & Billroth II & 23 & Infiltration mucosa. No metastasis & II c \\
M & 52 & Duodenal ulcer & Billroth II & 25 & Infiltration mucosa. No metastasis & II b Multicentric \\
M & 71 & Duodenal ulcer & Billroth II & 22 & Infiltration mucosa. No metastasis & II a-b \\
M & 70 & Duodenal ulcer & Billroth II & 35 & Infiltration mucosa. No metastasis & II a-b \\
M & 74 & Duodenal ulcer & Billroth II & 27 & Infiltration mucosa. No metastasis & II c \\
M & 52 & Duodenal ulcer & Billroth II & 26 & & \\
\hline
\end{tabular}

was detected at the first investigation and in three patients during follow up. Details of the patients with post-gastrectomy cancer are given in Table 2.

Two patients were inoperable, and one could have been radically resected but he had a positive lymph node in the operative specimen. These three patients died within two years of diagnosis.

Seven patients had radical curative resections and are still alive. Six of them had early carcinomas; in five the cancer was limited to the superficial mucosa-so called intramucosal carcinoma. In four of the patients with intramucosal carcinoma there was no suspicious lesion visible at endoscopy. In the other patient a suspicious polypoid lesion was seen at endoscopy. There was, however, some doubt about infiltration in the biopsies taken from this lesion (Fig.4). In the operative specimen no infiltration could be seen in the suspicious polypoid lesion, but intramucosal carcinoma was present in two sites elsewhere in macroscopically normal looking mucosa.

In all patients carcinoma was localised in the stomal area; in two patients with intramucosal carcinoma multiple foci of malignancy were present. In the patients with early carcinoma only in 12 of the 121 biopsies taken from the stomal area cancer could be shown.

\section{DYSPLASIA}

Epithelial dysplasia was present at the first endos-

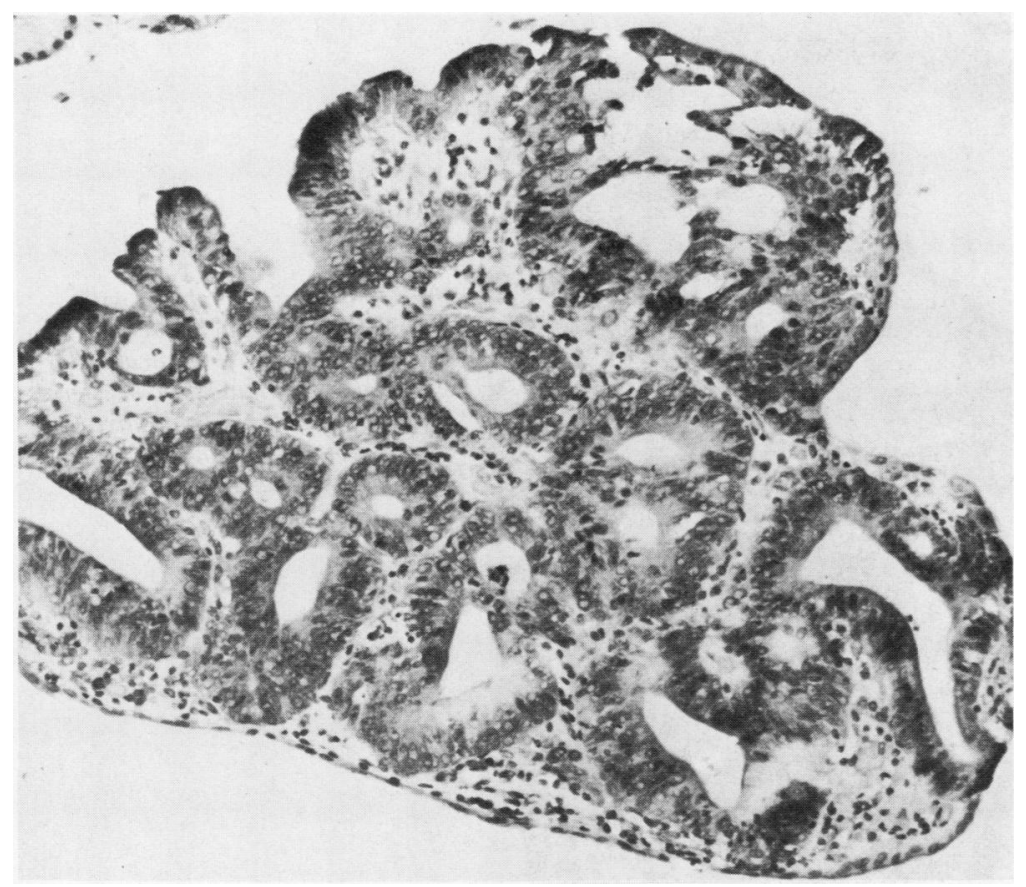

Fig. 4 Severe dysplasia. No infiltrative growth demonstrable. Haematoxylin and eosin. $\times 200$. 


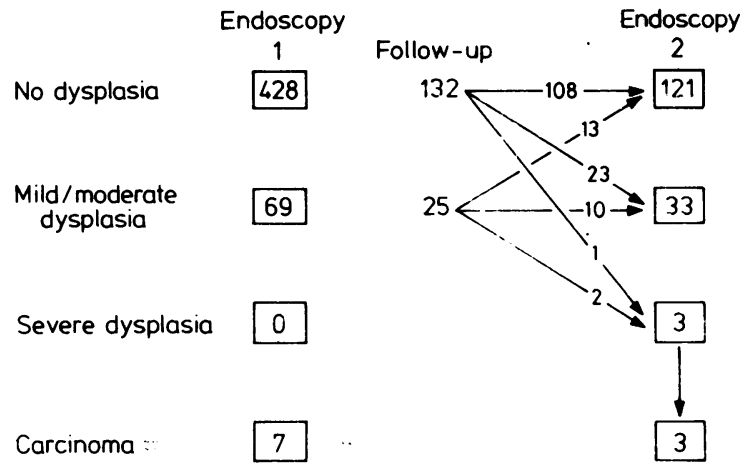

Fig. 5 Results of endoscopic-biopsy follow up in 157 patients who had undergone gastrectomy.

copy in the biopsies of 69 patients (13.7\%). In 157 patients follow up examinations were performed. The results are shown in Fig. 5. In two patients with severe dysplasia at the second endoscopy intramucosal cancer was detected at follow up at the site of preceding severe dysplasia.

\section{CASE 1}

A 49 year old man underwent Billroth II resection for duodenal ulcer in 1954. At the first endoscopy in 1977 no abnormalities were visible and only slight dysplasia was present in some of the biopsies from the stomal site. At the second endoscopy two years later again no abnormalities were seen, but one of the biopsies from the stomal site now showed severe dysplasia, possibly even carcinoma, although infiltrative growth could not be shown (Fig. 6). At the third endoscopy six months later an erosion was seen at the anastomosis near the lesser curve. Biopsies from this lesion were separately submitted for histopathological examination and showed typical severe dysplasia (Fig. 3). Six months later the same erosion was visible at endoscopy and one of the biopsies from this site now showed a picture which suggested a carcinoma. A total gastrectomy was performed and in the operative specimen a minute carcinoma with surrounding severe dysplasia was found in the depressed erosive mucosa.

\section{CASE 2}

A 66 year old man underwent a Billroth II resection for duodenal ulcer in 1946. At the first endoscopy in 1977 no abnormalities other than xanthelasmata were seen. No dysplasia was seen at routine histopathological examination of the biopsies. At the second endoscopy two years later severe dysplasia was present in one of the biopsies of the stomal site.

Endoscopy was repeated and multiple biopsies were taken clockwise around the stoma and submitted separately for histopathological examination. The localisation of the biopsy sites was designated

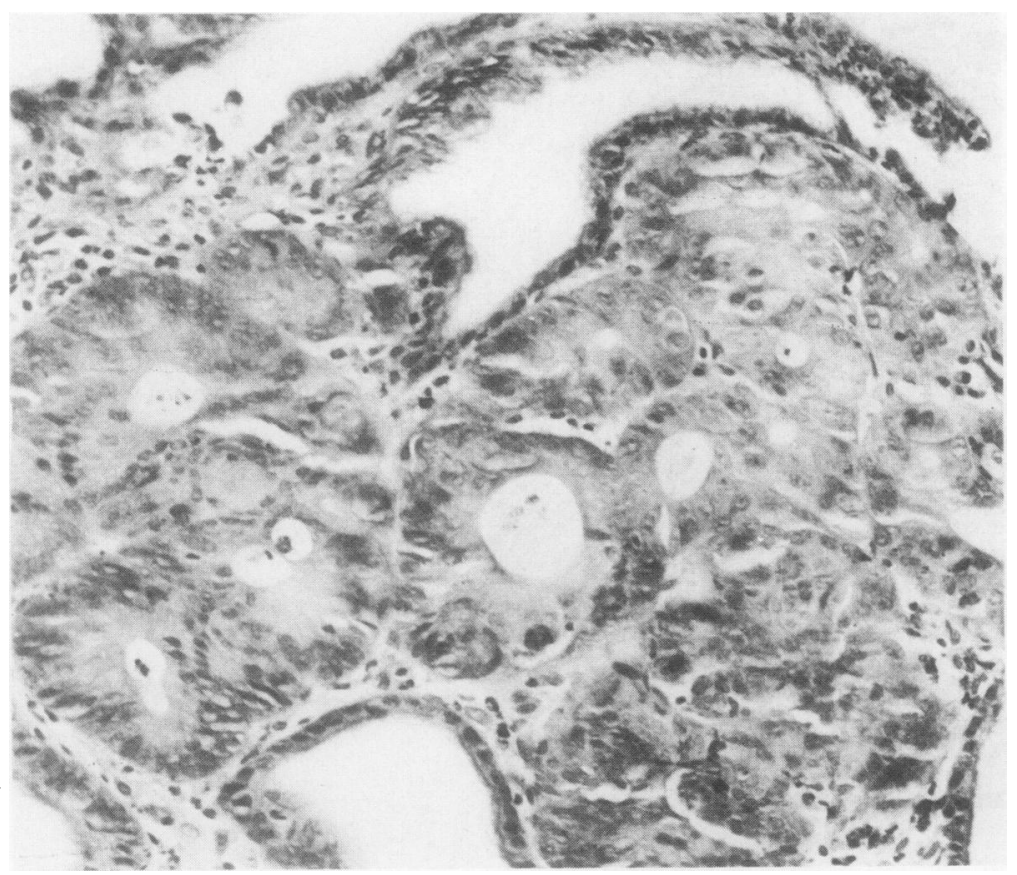

Fig. 6 Cribriform tubules with debris in the lumina, bordered by irregularly arranged atypical cells with pleiomorph nuclei; consistent with carcinoma, but infiltrative growth not demonstrable. Haematoxylin and eosin. $\times 250$. 


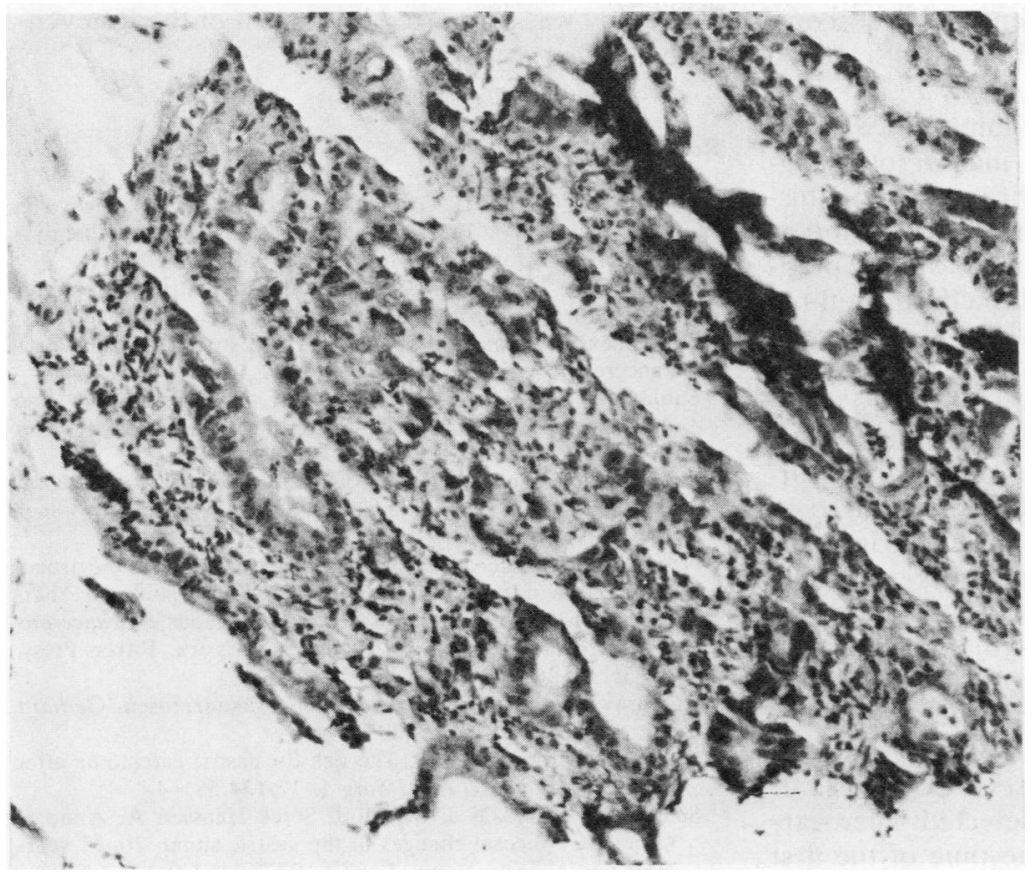

Fig. 7 This piece of tissue, taken at the first endoscopy in 1977, although badly damaged possibly originates from an eve of carcinoma. Haematoxylin and $\operatorname{eosin} \times 200$.

precisely by mapping and photographing. In one of the biopsies from the stomal region near the lesser curve a carcinoma could be seen. Some of the surrounding biopsies showed severe dysplasia. All the former slides were reviewed and one severely damaged piece of tissue, taken during the first endoscopy, now appeared to be suspicious of infiltrating carcinoma. (Fig. 7).

At the fourth endoscopy again no macroscopic suspicious lesions were seen, but now at two separate sites, one of which formerly showed only severe dysplasia, carcinoma could be seen. Owing to an intercurrent illness and the patient's hesitation for surgery total gastrectomy was performed almost one year later. In the operative specimen intramucosal carcinoma could be seen in the whole region of the preceding carcinoma and severe dysplasia.

Another patient with moderate dysplasia at the first investigation refused a second endoscopy and was followed elsewhere. Four years after our first endoscopy a carcinoma was detected. In the mean time the control examinations elsewhere had shown severe dysplasia.

In 23 other patients with previous mild or moderate dysplasia no progression was found during follow up. One hundred and thirty two patients without dysplasia at the first examination were followed: in 23 patients mild or moderate dysplasia was detected during follow up and in one (case 2) severe dysplastic changes were present at the second endoscopy.

\section{Discussion}

Endoscopic screening of 504 asymptomatic patients who had undergone gastrectomy revealed 10 $(1.98 \%)$ stump carcinomas, of which six turned out to be early cancers. Other endoscopic screening studies of post-gastrectomy patients have found gastric carcinomas in $0.8 \%, 3 \%$, and $3.7 \% .^{7-10}$ The yield of early gastric cancers in these studies was $0.8 \%, 1.7 \%$, and $2.7 \%$ respectively. Thus the overall yield of gastric cancer in the four studies was about $2 \%$ and that of early cancers $1.4 \%$. It is reasonable to doubt whether this is sufficient to advocate endoscopic screening in all postgastrectomy patients. Even in Western Europe, where a higher frequency of gastric cancer after gastric surgery has been shown convincingly, ${ }^{811-14}$ endoscopic mass screening of the population with previous gastric surgery does not seem justified. ${ }^{2}$ Therefore, the most important lesson from our endoscopic screening study of patients who have undergone gastrectomy is that early malignancy can be detected and that physicians should rely not so much on the endoscopic appearance but on the routine multiple biopsies. They should consider tak- 
ing multiple biopsies even when no endoscopic abnormalities are present. This has also been emphasised by others. ${ }^{910}$

One additional point of major importance is our finding of gastric dysplasia as a marker of malignancy. The precise clinical significance of this histopathological alteration is still insufficiently understood. Stokkeland et al ${ }^{10}$ were unable to show progression of mild or moderate dysplasia during a three year follow up study of patients who had undergone gastrectomy. Furthermore, the evolution of severe dysplasia remains unclear in this study. Savage et al ${ }^{15}$ found severe dysplasia in one post-gastrectomy patient following moderate dysplasia six months earlier. Oehlert et al ${ }^{5}$ reported regression of even severe dysplasia. It is, however, unclear from their study to what extent sampling errors could be excluded.

In cases 1 and 2 of our study carcinoma was found at well identified sites, which had previously showed severe dysplasia only in multiple biopsies from these sites. Such observations are strongly suggestive of carcinoma developing in areas of severe dysplasia. It may be, however, that an undetected microcarcinoma was already present at the time of the first endoscopy and that this spread over larger areas during the period of follow up.

True regression of severe dysplasia could not be shown in our study. We therefore believe that severe dysplasia is an irreversible premalignant lesion and marker for impending or already present malignancy. For patients with severe dysplasia more frequent endoscopic-biopsy surveillance seems mandatory. The significance of mild or moderate dysplasia remains unclear. Control examinations with an interval of two to three years in these patients are probably enough, as others have suggested.'

In conclusion, we have shown by this large scale endoscopic surveillance study that early carcinoma is detectable in the gastric remnant provided multiple biopsies are obtained and examined carefully. If severe dysplasia is present in the biopsies close surveillance is necessary. Either malignancy is already present somewhere in the stomach or it is likely that malignancy will develop soon.
This study was supported by a grant of the Praeventifonds.

\section{References}

' Morson BC, Sobin LH, Grundmann E, Johansen A, Nagayo T, Serck-Hanssen A. Precancerous conditions and epithelial dysplasia in the stomach. J Clin Pathol 1980;33:711-21.

${ }^{2}$ Logan RFA, Langman MJS. Screening for gastric cancer after gastric surgery. Lancet 1983;ii:667-70.

${ }^{3}$ Hermanek P, Riemann JF. The operated stomach-still a precancerous condition? Endoscopy 1982;14:113-4.

4 Saukkonen M, Sipponen P, Kekki M. The morphology and dynamics of the gastric mucosa after partial gastrectomy. Ann Clin Res 1981;13:156-8.

s Oehlert W, Keller P, Henke M, Strauch M. Gastric mucosal dysplasia: What is its clinical significance. Front Gastrointest Res 1979;4:173-82.

- Nagayo T. Precancerous changes of the stomach from the aspect of dysplasia of the gastric mucosa-histological study. In: Sherlock P, Morson BC, Barbara L, Veronesi U, eds. Precancerous lesions of the gastrointestinal tract. New York: Raven Press, 1983:115-26.

${ }^{7}$ Rösch W, Elster K. Gastrointestinale Präkanzerosen. Gerhard Witzstrock Verlag 1977:42-7.

${ }^{8}$ Domellöf L, Janunger KG. The risk for gastric carcinoma after partial gastrectomy. Am J Surg 1977;134:581-4.

- Schrumpf E, Stadaas J, Myren J, Serck-Hanssen A, Anne S, Osnes M. Mucosal changes in the gastric stump 20-25 years after partial gastrectomy. Lancet 1977;ii:467-9.

${ }^{10}$ Stokkeland M, Schrumpf E, Serck-Hanssen A, Myren J, Osnes $M$, Stadaas J. Incidence of malignancies of the Billroth II operated stomach. A prospective follow up. Scand J Gastroenterol 1981; suppl 16:169-71.

" Kühlmayer R, Rokitansky O. Das Magenstumpfkarzinom als Spätproblem der Ulcuschirurgie. Langenbecks Arch Chir 1954;278:361-75.

${ }^{12}$ Hilbe G, Salzer GM, Hussl H, Kutschera H. Die Karzinomgefährdung des Resektionsmagens. Langenbecks Arch Chir 1968;323: 142 .

${ }^{13}$ Stalsberg H, Taksdal S. Stomach cancer following gastric surgery for benign conditions. Lancet 1971;ii:1175-7.

14 Myren J. Markers of cancer risk and surveillance of the gastric stump. In: Sherlock P, Morson BC, Barbara L, Veronesi U, eds. Precancerous lesions of the gastrointestinal tract. New York: Raven Press, 1983:195-203.

is Savage A, Jones S. Histological appearances of the gastric mucosa 15-27 years after partial gastrectomy. J Clin Pathol 1979;32:179-86.

Requests for reprints to: Dr GJA Offerhaus, Department of Gastroenterology (C-2), Academic Medical Centre, Meibergdreef 9, 1105 AZ Amsterdam, The Netherlands. 